\title{
Immunomodulatory Potential of Cannabidiol in Multiple Sclerosis: a Systematic Review
}

\author{
Alessia Furgiuele $^{1} \cdot$ Marco Cosentino $^{1}$ (D) Marco Ferrari $^{1} \cdot$ Franca Marino ${ }^{1}$ \\ Received: 16 December 2020 / Accepted: 6 January 2021 / Published online: 25 January 2021 \\ (C) The Author(s) 2021
}

\begin{abstract}
Multiple sclerosis (MS) is the most common chronic autoimmune disease of the central nervous system. Efficacy of treatments for MS is associated with risk of adverse effects, and effective and well-tolerated drugs remain a major unmet need. Cannabis (Cannabis sativa L., fam. Cannabaceae) and cannabinoids are popular among MS patients to treat spasticity and pain. Cannabinoids are endowed with remarkable immunomodulating properties, and in particular the non-psychotropic cannabinoid cannabidiol (CBD) is increasingly recognized as anti-inflammatory and immunosuppressive, nevertheless with excellent tolerability even at high doses. In this systematic review, we retrieved and critically evaluated available evidence regarding the immune and disease-modifying effects of CBD in experimental autoimmune encephalomyelitis (EAE) and in MS. Evidence in rodent models of EAE strongly supports CBD as effective, while clinical evidence is still limited and usually negative, due to paucity of studies and possibly to the use of suboptimal dosing regimens. Better characterization of targets acted upon by CBD in MS should be obtained in ex vivo/in vitro studies in human immune cells, and higher doses should be tested in well-designed clinical trials with clinically relevant efficacy endpoints.
\end{abstract}

Keywords Multiple sclerosis $\cdot$ Experimental autoimmune encephalomyelitis $\cdot$ Cannabidiol $\cdot$ Immunomodulation

\section{Introduction}

Multiple sclerosis (MS) is the most common chronic autoimmune disease of the central nervous system (CNS), affecting more than two million people worldwide. MS has unknown etiology, is at least as twice as common in women than in men, and usually begins in adults $20-45$ years of age, developing through a highly heterogeneous and unpredictable course: neurological deficits are usually reversible in the early phases but over time evolve in progressive neurological deterioration. Based on the clinical course, MS is usually divided in four major forms: (i) relapsing-remitting MS (RRMS), which affects $85 \%$ of MS patients, (ii) secondary progressive MS (SPMS), which may develop in some RRMS patients, (iii) primary progressive MS (PPMS), which affects approximately $10 \%$ of MS patients, and (iv) progressive-relapsing MS

Marco Cosentino

marco.cosentino@uninsubria.it

1 Center for Research in Medical Pharmacology and Center for Research in Neuroscience, University of Insubria, Via Ottorino Rossi n. 9, 21100 Varese, VA, Italy
(PRMS), occurring in fewer than 5\% of patients (Dobson and Giovannoni 2019; Reich et al. 2018; Oh et al. 2018; Thompson et al. 2018).

MS is characterized by inflammation, demyelination and neurodegeneration, which are regarded as resulting from autoreactive myelin-specific $\mathrm{T}$ lymphocytes entering the CNS. T cells undergo reactivation in the CNS by local antigen presenting cells, eventually triggering an inflammatory cascade including release of proinflammatory cytokines such as tumor necrosis factor (TNF)- $\alpha$, and interferon (IFN)- $\gamma$, recruitment of additional inflammatory cells ( $\mathrm{T}$ cells, monocytes, B cells), persistent activation of macrophages resulting in oligodendrocyte death and further demyelination (Yamout and Alroughani 2018; Hemmer et al. 2002).

MS has no known cure so far, nonetheless several immunomodulatory and immunosuppressive treatments have proven helpful at slowing disease progression and reducing relapse rates, including IFN- $\beta$, glatiramer acetate, dimethyl fumarate, the type II topoisomerase inhibitor mitoxantrone, the inhibitor of pyrimidine synthesis teriflunomide, the purine analog cladribine, the sphingosine-1-phosphate (S1P) receptor agonists fingolimod, siponimod, and ozanimod, and several monoclonal antibodies such as natalizumab, alemtuzumab, 
ocrelizumab. The clinical efficacy and risk-benefit ratio of all these treatments are however still far from optimal, and the more effective medications have a higher risk of serious adverse reactions (Gholamzad et al. 2019; Thompson et al. 2018).

Besides disease-modifying treatments targeting pathogenetic mechanisms, management of MS includes a wide array of pharmacological and non-pharmacological approaches aimed at minimising disease impact while maximising quality of life (Gholamzad et al. 2019; Thompson et al. 2018). Among pharmacological treatments for the symptomatic management of MS, cannabis (Cannabis sativa L., fam. Cannabaceae) and its derivatives, such as $\Delta^{9}$-tetrahydrocannabinol $\left(\Delta^{9}-\right.$ THC) and the non-psychotropic cannabinoid cannabidiol (CBD), are increasingly recognized as effective to treat spasticity and pain (Yadav et al. 2014). In 2010, nabiximols - a formulated cannabis extract containing $\Delta^{9}$ THC and CBD in a 1:1 ratio - was licensed in UK for the treatment of spasticity due to MS, and it is currently marketed under the trade name of Sativex ${ }^{\circledR}$ in more than 25 countries outside the USA (https://www.gwpharm.co.uk/healthcareprofessionals/sativex). The use of cannabis and cannabinoids is widespread and well accepted among patients with MS. Epidemiological studies show that MS patients increasingly use cannabis preparations for a range of symptoms, including sleep disturbances, pain, anxiety, spasticity and even depression. Across the surveys, current use of cannabis is reported by $20-60 \%$ of people with MS, and $50-90 \%$ are in favour of legalization, would consider usage if it were legal, and ask for more scientific evidence (Schabas et al. 2019; Brenton et al. 2018; Loraschi et al. 2016; Banwell et al. 2016).

Several lines of evidence indicate that cannabinoids have immunomodulatory and immunosuppressive properties, suggesting these drugs as potential therapeutics in chronic inflammatory diseases (Klein 2005), and cannabinoid receptors have been recently proposed as therapeutic targets for autoimmune diseases including MS (Gonçalves and Dutra 2019). Cannabis use in clinical practice has been historically hampered by the addictive potential of $\Delta^{9}$-THC, as well as by its psychoactive effects, such as cognitive impairment, psychosis, dysphoria, and anxiety. CBD however is devoid of any drug abuse liability (Babalonis et al. 2017) and is well tolerated in humans up to $6000 \mathrm{mg} /$ day p.o. (Taylor et al. 2018; Iffland and Grotenhermen 2017; Bergamaschi et al. 2011). CBD has recently received Food and Drug Administration (FDA) and European Medicines Agency (EMA) approval for seizures associated with Lennox-Gastaut syndrome or Dravet syndrome (https://www.epidiolex.com/, Chen et al. 2019). CBD has prominent anti-inflammatory and even immunosuppressive effects (Nichols and Kaplan 2020; Zurier and Burstein 2016; Burstein 2015), and evidence exists that it could be beneficial in chronic inflammatory conditions, such as inflammatory bowel disease (Esposito et al. 2013), rheumatoid arthritis (Lowin et al. 2019), neurodegenerative disorders (Cassano et al. 2020), and even in acute inflammation due to SARS-CoV-2 infection (Costiniuk and Jenabian 2020). Despite the widespread use of CBD for the symptomatic management of MS, the possible relevance of its immunomodulatory properties and its potential as disease-modifying drug in MS patients has so far received little consideration.

In the present review, after a thorough description of the complex pharmacology of CBD, which includes several molecular targets besides cannabinoid receptors, available preclinical and clinical evidence about the immune effects of CBD in MS is presented and discussed, to provide a summary of available knowledge and define a roadmap for the extensive assessment of the immunomodulatory potential of CBD in MS patients.

\section{Pharmacology of CBD}

Pharmacodynamics CBD is a natural cannabinoid isolated in 1940 from cannabis plants (Mechoulam et al. 1970) (Fig. 1). It is the major non-psychoactive cannabinoid and occurs naturally in appreciable amounts in the plant leaves and flowers, accounting for up to $40 \%$ of the plant's extracts obtained from newly developed varieties poor in $\Delta^{9}$-THC (Andre et al. 2016).

CBD has a quite complex receptor pharmacology (Table 1). CBD is indeed a weak activator of cannabinoid receptors type $1(\mathrm{CB} 1)$ and type $2(\mathrm{CB} 2)$. Actually, $\mathrm{CBD}$ may also act as a negative allosteric modulator of the $\mathrm{CB} 1$ receptor, and as an inverse agonist of the $\mathrm{CB} 2$ receptor (Pertwee 2008). CBD however also acts on several mammalian transient receptor potential (TRP) channels, including TRPV ("V" for vanilloid), TRPA ("A" for ankyrin), and TRPM ("M" for melastatin) (Muller et al. 2019). CBD acts as an agonist on TRPV1, resulting in capsaicin-like analgesia (Iannotti et al. 2014). CBD may also bind and activate TRPV2, TRPV3, and TRPA1, while being an antagonist at TRPM8 (Muller et al. 2019). CBD is an agonist of the peroxisome proliferator-activated receptor (PPAR) $\gamma$, which a

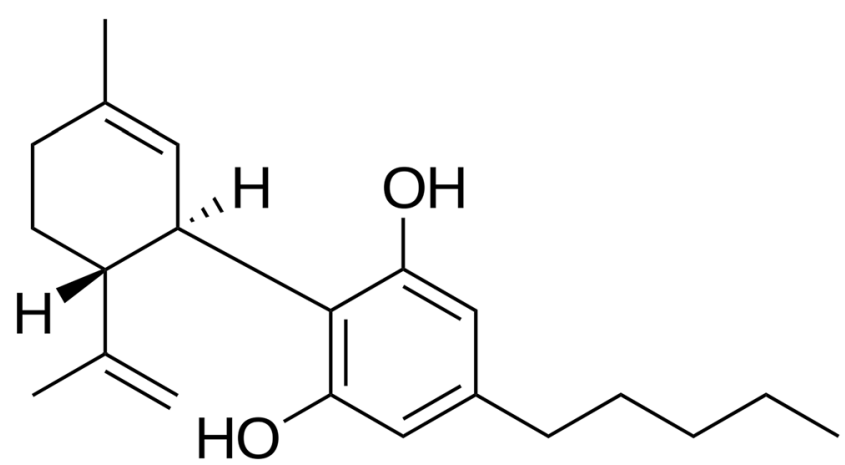

Fig. 1 Chemical structure of $\mathrm{CBD}$ 
Table 1 CBD pharmacology

\begin{tabular}{lll}
\hline Target & Action & Reference \\
\hline CB1 & Weak agonist negative Allosteric modulator & Pertwee (2008) \\
CB2 & Weak agonist inverse agonist & Pertwee (2008) \\
TRPV1, TRPV2, TRPV3, TRPA1 & Agonist & Muller et al. (2019) \\
TRPM8 & Antagonist & Muller et al. (2019) \\
PPAR $\gamma$ & Agonist & O'Sullivan et al. (2009) \\
GPR55 & Antagonist & Atalay et al. (2019) \\
GPR3, GPR6, GPR12 & Inverse agonist & Atalay et al. (2019) \\
5-HT1a & Agonist & Russo et al. (2005) \\
$\mathrm{A}_{2 \mathrm{~A}}$ & Agonist & Ribeiro et al. (2012) \\
$\mu$ and $\delta$ opioid receptors & Allosteric modulator & Kathmann et al. (2006) \\
\hline
\end{tabular}

Abbreviations: $C B$ cannabinoid receptors, $T R P$ transient receptor potential channels, " $V$ " for vanilloid, " $A$ " for ankyrin, and ' $M$ ' for melastatin, $P P A R \gamma$ peroxisome proliferator-activated receptor $\gamma, G P R$ G protein-coupled orphan receptors, 5-HTla 5-hydroxytryptamine receptor $1 \mathrm{a}, A_{2 A}$ adenosine receptor $2 \mathrm{~A}$

ligand-inducible transcription factor belonging to the superfamily of nuclear receptors (O'Sullivan et al. 2009). CBD also binds some $\mathrm{G}$ protein-coupled orphan receptors (GPR). In particular, it has been reported to act as an antagonist at GPR55, and as an inverse agonist at GPR3, GPR6 and GPR12 (Atalay et al. 2019). Finally, CBD may be an agonist at serotonin (5-hydroxytryptamine, 5-HT) receptors 1a (Russo et al. 2005), and at the adenosine $\mathrm{A}_{2 \mathrm{~A}}$ receptors (Ribeiro et al. 2012), and possibly an allosteric modulator at $\mu$ and $\delta$ opioid receptors (Kathmann et al. 2006).

Remarkably, besides its direct effects on multiple receptor targets, CBD has prominent direct and indirect antioxidant effects (Atalay et al. 2019) as well as the ability to block the enzyme fatty acid amide hydrolase, resulting in an inhibited degradation and therefore increased levels of anandamide. a fatty acid neurotransmitter acting as agonist on CB1 and CB2, as well as on several other receptor targets, including among others TRPV1, TRPM8, and GPR55 (Lim et al. 2017).

Pharmacokinetics CBD pharmacokinetics (PK) has been recently systematically reviewed by Millar et al. (2018), who retrieved, summarized and discussed all articles reporting PK data of CBD in humans. The authors conclude that, despite the widespread clinical use of CBD, information about its $\mathrm{PK}$ is limited and inconsistent, and highlight the need for thorough studies aimed at the better understanding of key PK parameters such as bioavailability and half-life.

Pharmacogenetics CBD acts on many molecular targets (Table 1), most of them with evidence of genetic variability linked to some functional consequences. For instance, CB1 and CB2 have been extensively studied for involvement in cannabis dependence (Hryhorowicz et al. 2018), mutations in TRPV channels are known from genetic pain research and may modulate the effects of experimental analgesics targeting
TRPV1 or TRPV3 (Lötsch and Geisslinger 2011), PPAR $\gamma$ genetic variants are a promising target for precision medicine in Type 2 diabetes mellitus (Khatami et al. 2019). No studies exist so far investigating the role of such genetic variants in the effects of $\mathrm{CBD}$, nevertheless, pharmacogenomic clinical trials of cannabinoids are currently ongoing, such as those examining the effects of the catechol-O-methyl-transferase (COMT) gene on the effects of CBD (NCT02116010 n.d.; NCT02492074 n.d.).

Compared to the lack of pharmacogenetic studies about CBD targets, more evidence exists concerning CBD PK. CBD absorption and distribution are influenced by $\mathrm{P}$ glycoprotein (P-gp), an efflux protein encoded by $A B C B 1$ gene, also known as multidrug resistance gene (MDR1), located in chromosome7q21 and composed of 28 exons (Hoffmeyer et al. 2000). SNPs in the $A B C B 1$ gene such as rs2032582 (c.2677G T > A), rs1045642 (c.3435C > T), and rs1 128503 (c.1236 C > T) are known to modify P-gp expression and activity and in turn PK of many drugs. No information is however available about their potential relevance for CBD PK (Rui-Jian et al. 2017). CBD is metabolized by cytochrome P450 (CYP450) superfamily enzymes, and in particular by CYP3A4 and CYP2C9 (Stout et al., 2014), which are encoded by $C Y P 2 C 9$ and $C Y P 3 A 4$ genes. To date, 60 polymorphic alleles of the CYP2C9 gene have been described, the most frequent being CYP2C9*2 (c.430 C $>$ T), and CYP2C9*3 (c.1075 A > C) which lead to decreased enzyme activity and poor metabolizer phenotype (Jarrar and Lee 2014). In the case of CYP3A4 gene, 26 polymorphic alleles are known, and CYP3A4*2, CYP3A4*11, CYP3A4*12, CYP3A4*17 are the most common, resulting in reduced enzyme activity (Werk and Cascorbi 2014). Unfortunately, no information is so far available on the effect of these SNPs on CBD PK in humans. UDP-glucuronosyltransferase (UGT) enzyme family is also involved in CBD biotransformation (Stout and Cimino 2014), in particular UGT1A9, UGT2B7, and 
UGT2B17. Important SNPs in the UGT1A9 gene such as UGT1A $9 * 3, * 4$, and UGT1A $9 * 5$ lead to the reduction or suppression of enzymatic activity (Olson et al. 2009). However, CBD glucuronidation has a minor role in overall elimination of the drug (Mazur et al. 2009), therefore genetic variants in UGT enzymes are unlikely to affect CBD PK to a major extent.

\section{Aim}

In the present review, we systematically retrieved and critically evaluated available evidence regarding the immune effects and the disease-modifying activity of CBD in MS and in experimental autoimmune encephalomyelitis (EAE), its preclinical animal model, to provide a state-of-the-art compendium of the immunomodulatory potential of CBD in MS.

\section{Search Strategy}

This systematic review was conducted in accordance with the PRISMA statement (Moher et al. 2009). Search algorithm was obtained by combining terms related to "cannabidiol" with those related to "multiple sclerosis" or "experimental allergic encephalomyelitis" as shown in Table 2, and search was thereafter performed in PubMed, Scopus and Web of Science databases (Fig. 2). References identified through this process were subsequently scanned for selection criteria. Inclusion criteria included studies of the peripheral and central immune effects of CBD, either pure or in botanical extracts, alone or together with other drugs. Excluded topics included review articles, duplicates, and studies of synthetic analogues, or metabolites of CBD. Thereafter, reference lists of the included articles were screened for additional reports. Neither language nor year restrictions was applied and all reports issued in the period up to July 29, 2020 were included.

\section{Results}

Our literature search led to a total of 1808 reports. After screening for relevant titles and abstracts, 29 papers were assessed for full-text eligibility, and 26 studies were finally included in the review (Fig. 2). All the records screened are listed as supplementary material (Supplementary Table 1).

\section{Preclinical Studies}

We found a total of 20 in vivo and ex vivo/in vitro studies of CBD in preclinical models of MS (Table 3). Most animal studies were performed in $\left(\mathrm{MOG}_{35-55}\right)$-induced EAE in $\mathrm{C} 57 \mathrm{BL} / 6 \mathrm{~J}$ mice. Individual studies however were also performed in EAE induced in mice by means of $\mathrm{MSCH}$ (Buccellato et al. 2011; Duchi et al. 2013), PLP $139-151$ (Gallily and Yekhtin 2019), TMEV (Mecha et al. 2013), and cuprizone (Sajjadian et al. 2017). One study made use of C57BL/6 J mice with adoptively transferred EAE (González-García et al. 2017), and another one was performed in Lewis rats with protein gp (69-88)-induced EAE (Zhou et al. 2019).

CBD was given i.p. in 12 out of 15 studies, most often at the dose of $5 \mathrm{mg} / \mathrm{kg} /$ day (6 studies), however also up to $20 \mathrm{mg} / \mathrm{kg} /$ day (Elliott et al. 2018), with highly variable schedules, administration beginning from immediately up to even 32-68 days after EAE induction (Buccellato et al. 2011), and lasting from 3 up to 60 days (Gallily and Yekhtin 2019). In

Table 2 Search algorithm for database screening

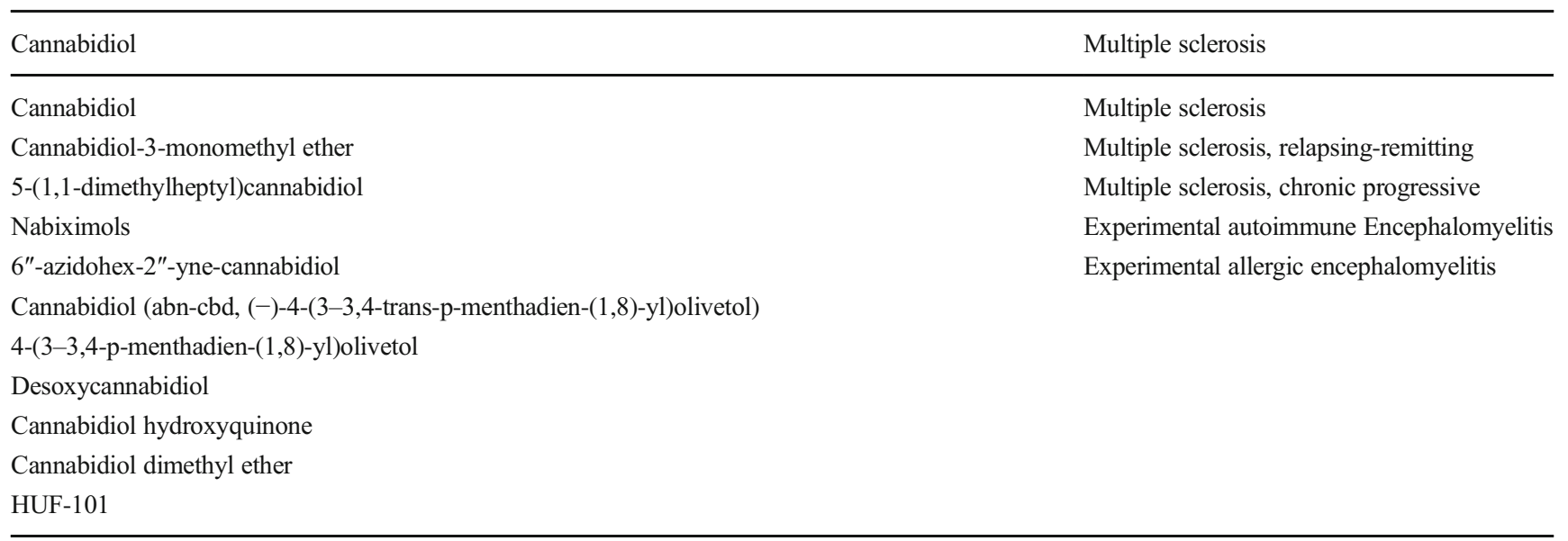

https:/www.ncbi.nlm.nih.gov/mesh/?term=cannabidiol

https://www.ncbi.nlm.nih.gov/mesh/?term=multiple+sclerosis

https://www.ncbi.nlm.nih.gov/mesh/?term=experimental+allergic+encephalomyelitis 
Fig. 2 Flow diagram of literature search

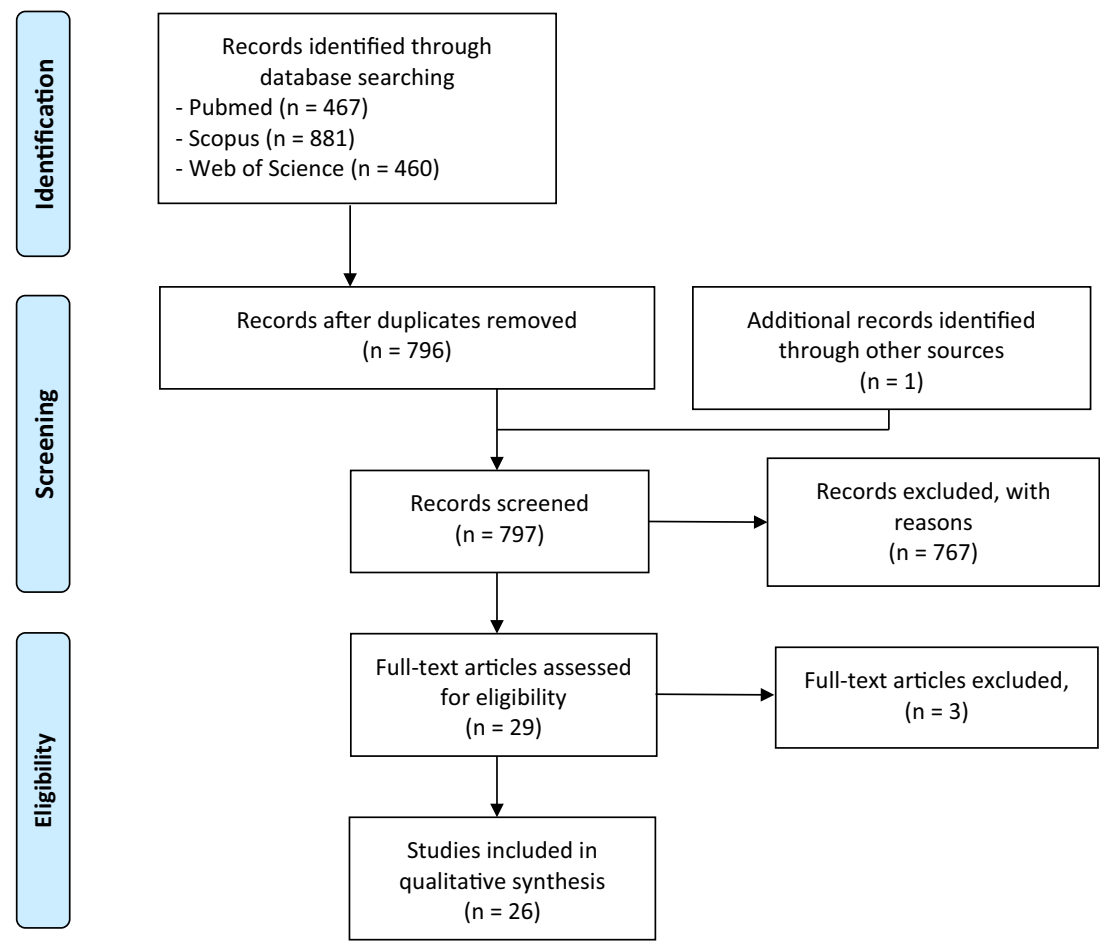

One study (Gallily and Yekhtin 2019) compared CBD to the anti-MS drug glatiramer showing that they were effective to the same extent in reducing EAE.

Preclinical investigation of CBD in EAE also included seven studies performed in ex vivo/in vitro models of encephalitogenic lymphocytes (Table 3 ), all based on $\mathrm{T}$ cells from lymph nodes or spleen of mice with $\left(\mathrm{MOG}_{35-55}\right)$-induced EAE, except for one which used astrocytes from TMEVIDD SJL/J mice (Mecha et al. 2013). CBD was always used at concentrations ranging from 0,1 to $10 \mu \mathrm{M}$, usually resulting in decreased proliferation and increased apoptosis of cells, as well as in inhibition of proinflammatory and activation of antiinflammatory pathways. Only few studies investigated the molecular targets mediating CBD effects. Kozela et al. excluded the contribution of either CB1, CB2, 5-HT1A, TRPV1 or PPAR $\gamma$ in CBD-dependent reduction of IL-17 secretion from T cells (Kozela et al. 2013), or of CB1 or CB2 in CBD-dependent inhibition of $\mathrm{T}$ cell proliferation (Kozela et al. 2011). No involvement of GPR55, CB1, or CB2 receptors was reported also by González-García et al. (2017), who studied CBD-induced inhibition of $\mathrm{MOG}_{35-55} / \mathrm{IL}$-12-induced IL-6 secretion and increased apoptosis in mouse encephalitogenic spleen cells, while Mecha et al. (2013) suggested a contribution by $\mathrm{A} 2 \mathrm{~A}$ receptors in $\mathrm{CBD}$-induced reduced of CCL2 secretion from mouse astrocytes.

\section{Clinical Studies}

Our search provided a total of six studies performed in MS patients and/or on immune cells obtained from patients 


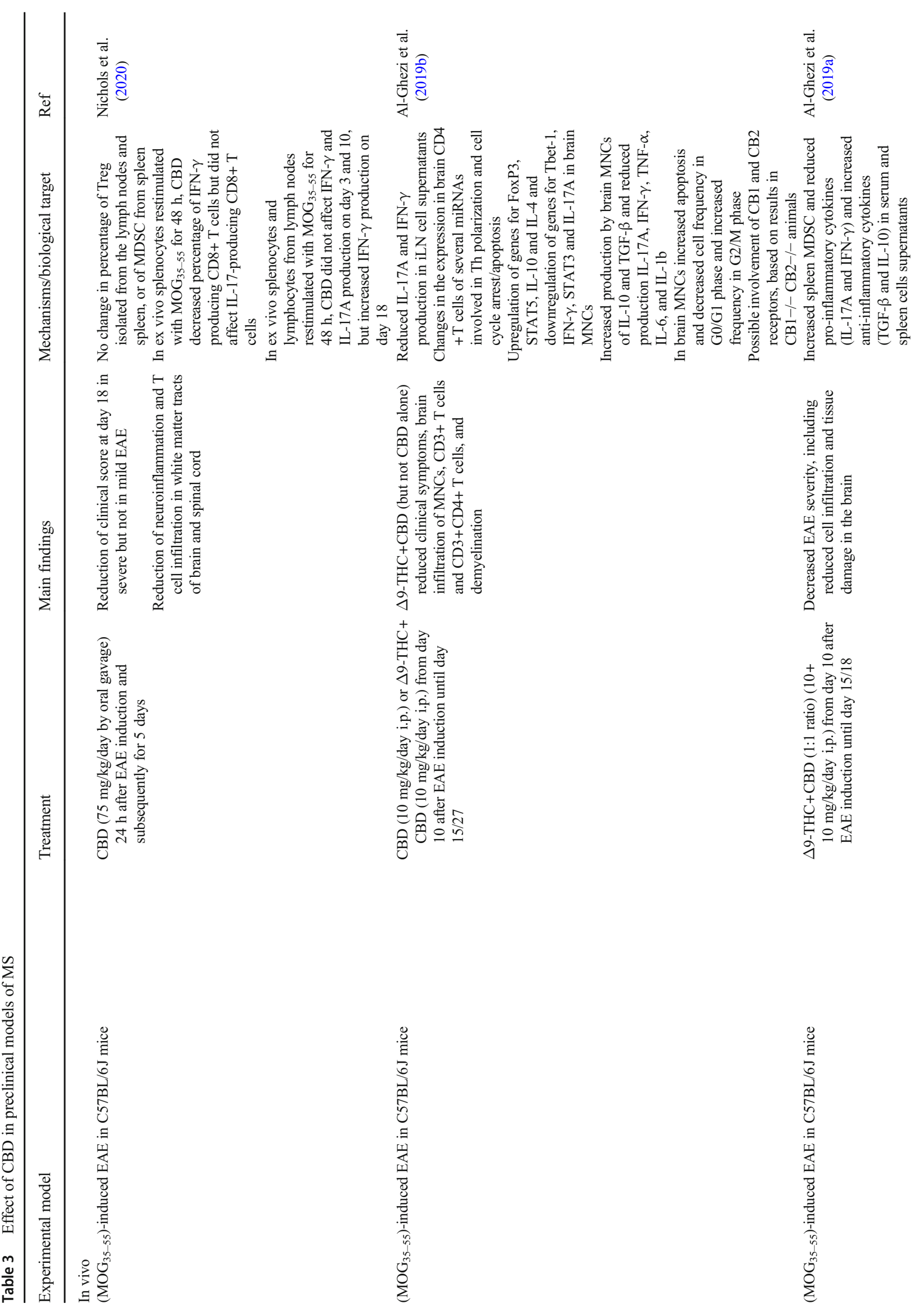




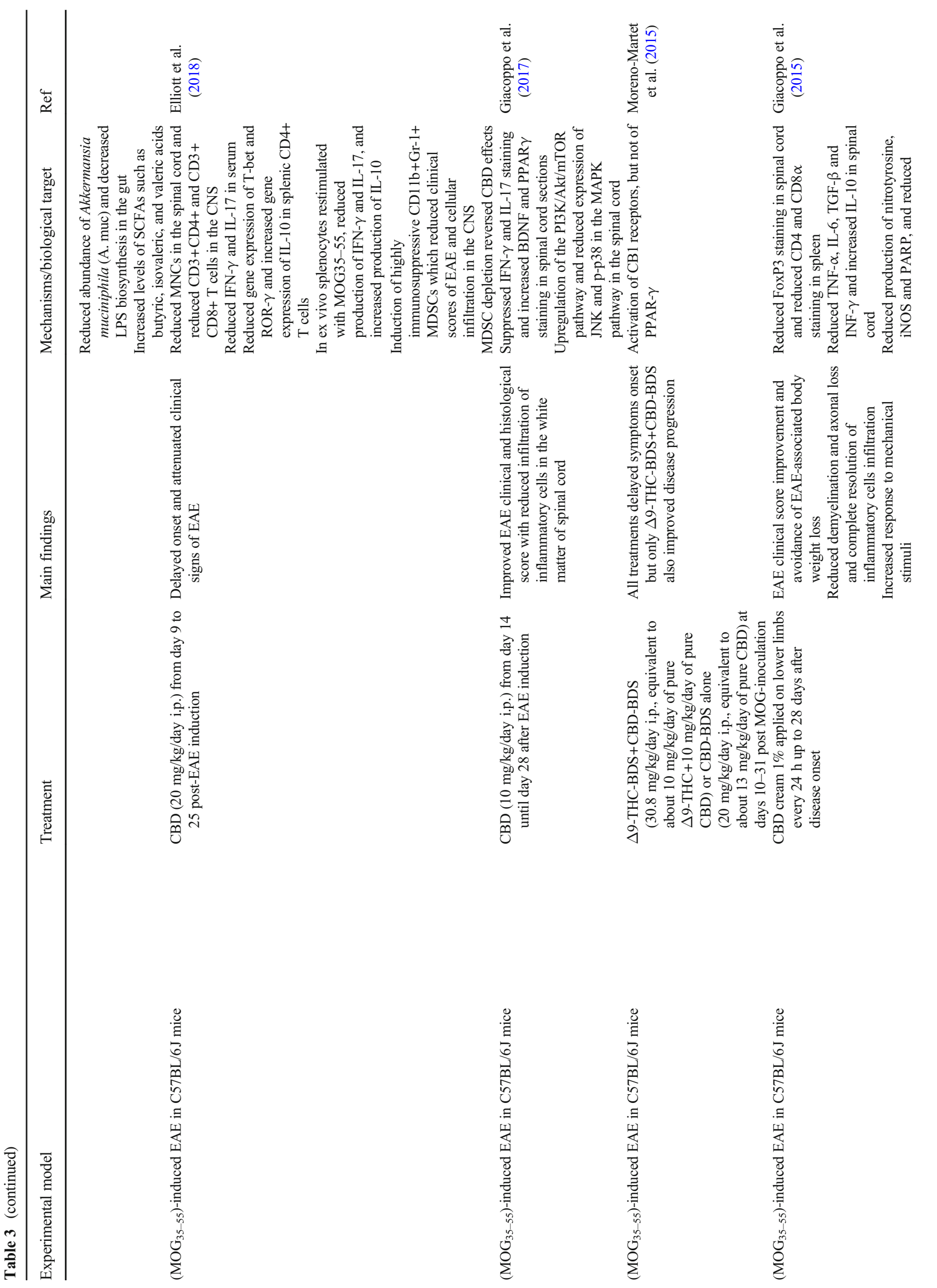




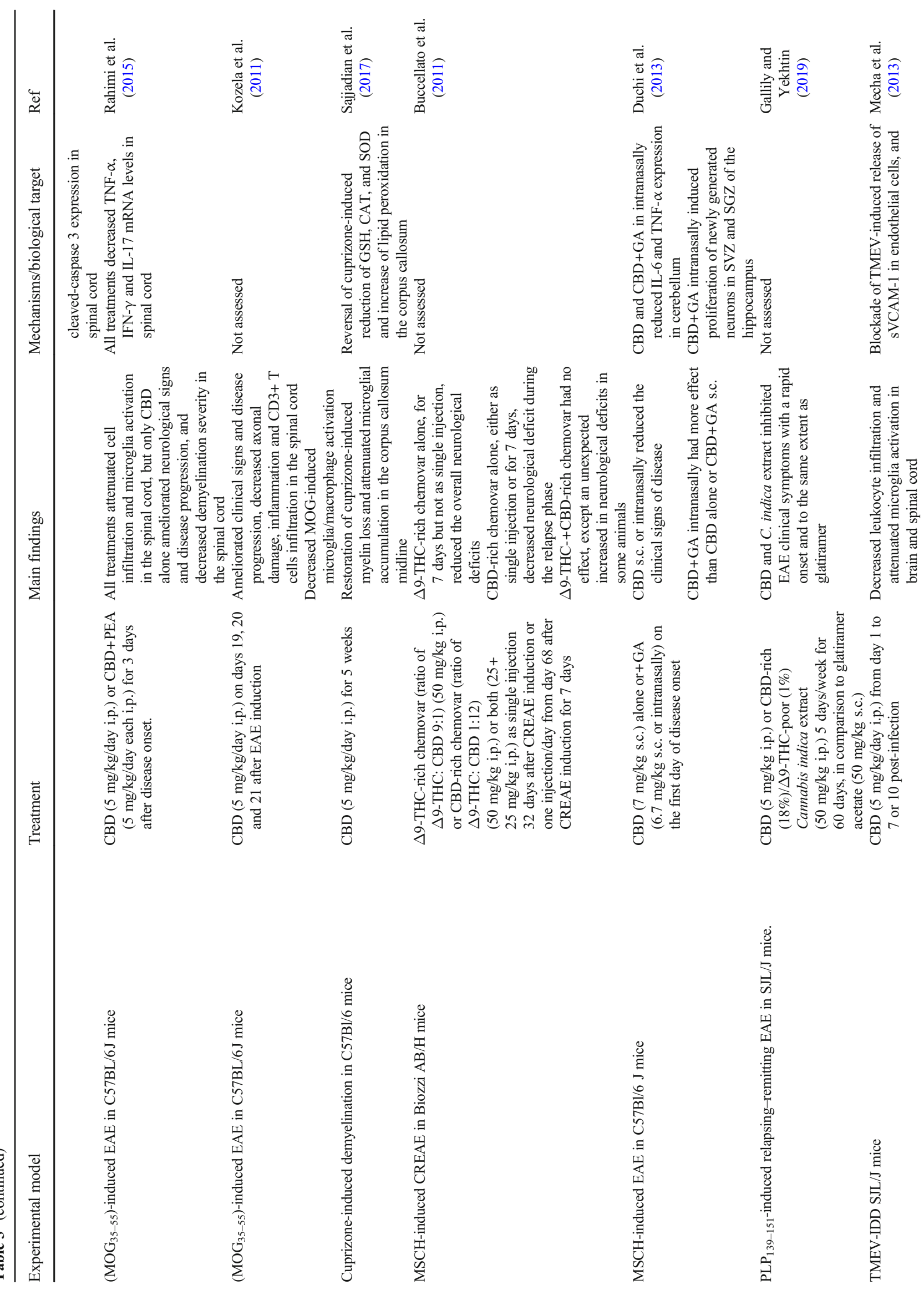




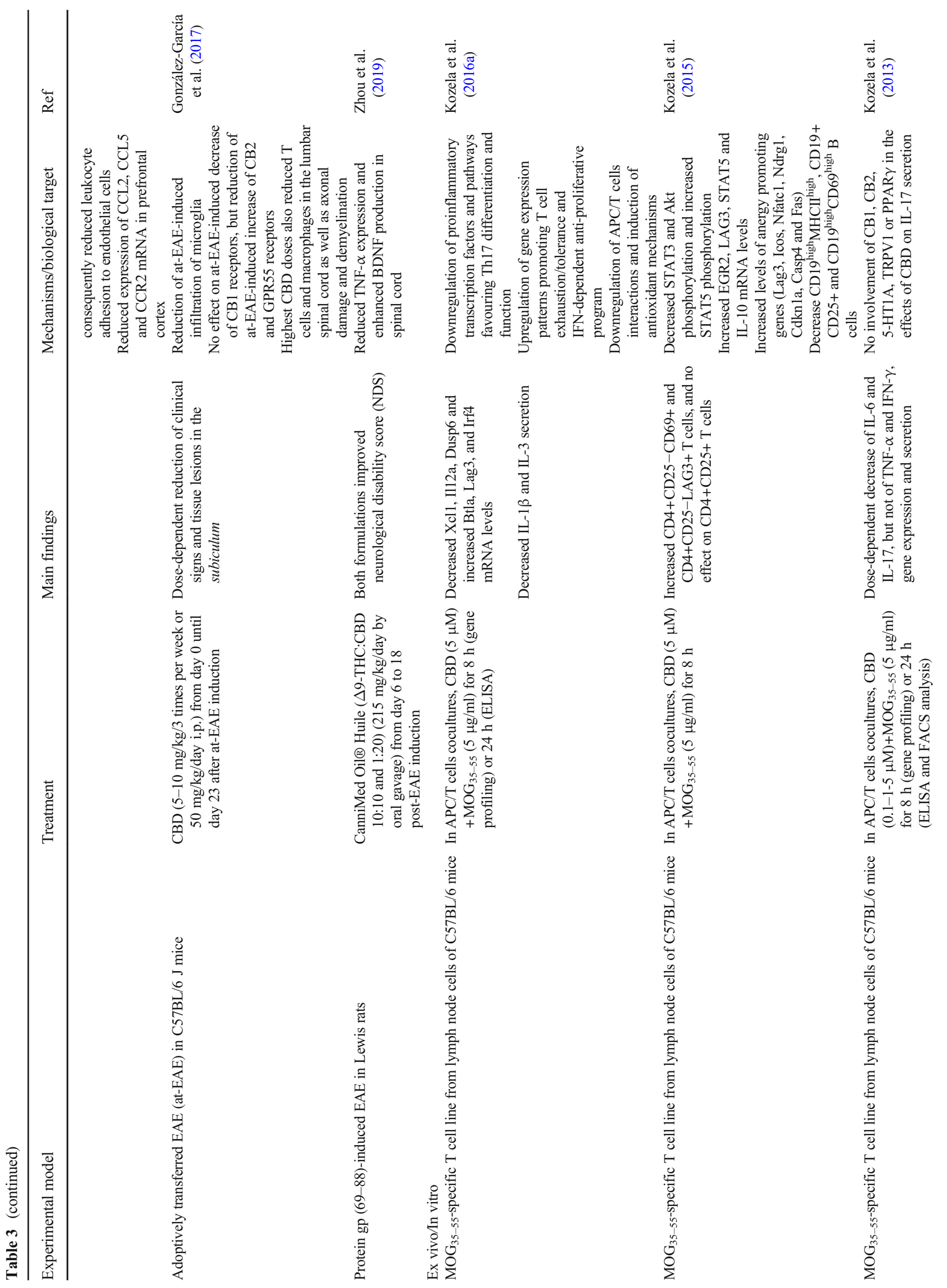




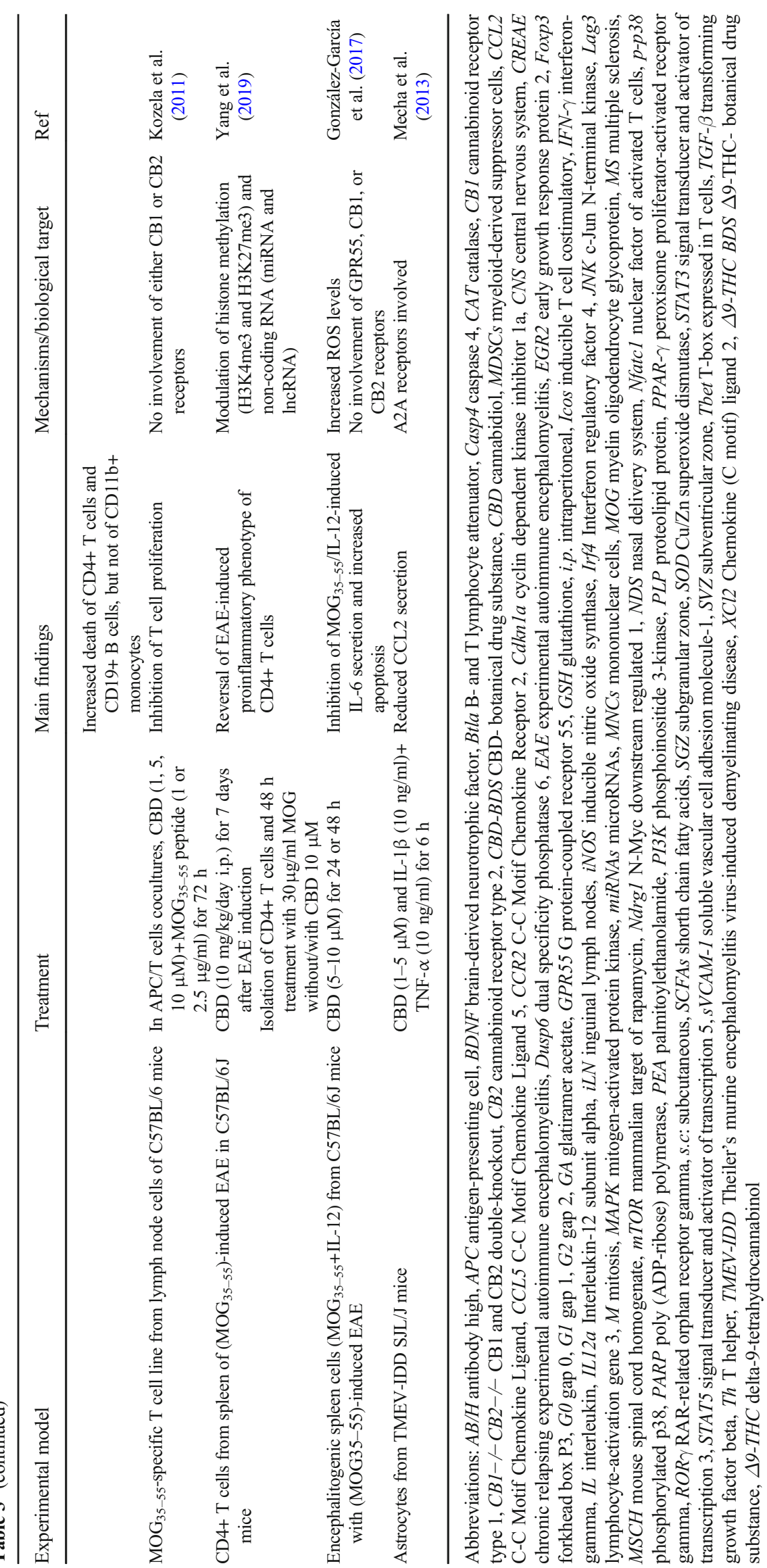


(Table 4).Of these, four studies examined the peripheral immune profile of patients treated with various cannabinoid preparations, one used CBD in ex vivo cultures of PBMC from patients and one did both.

Out of the five studies in patients, three were performed in small groups of subjects treated with nabiximols (a specific Cannabis extract approved in 2010 as a botanical drug with the trade name of Sativex to treat spasticity and pain in MS, and which is administered by mouth spray containing $2,7 \mathrm{mg}$ of $\triangle 9$-THC and 2,5 $\mathrm{mg}$ of CBD per puff). All the three studies were observational, nabiximols being given according to approved indications for periods of 4-6 weeks (Sorosina et al. 2018; Santoro et al. 2017; Centonze et al. 2009). As such, they included patients with different types of MS (for instance, RRMS, PPMS, SPMS in the study by Sorosina et al. (2018)), or both untreated and treated with IFN- $\beta$ (for instance, in the study by Santoro et al. (2017)). None of these studies reported any significant effect on peripheral immunity, and in particular Centonze et al. (2009) included detailed results on the immune profile of the 20 patients recruited, showing no modification of either CD3+, CD14+, CD19+, CD56+, $\mathrm{CD} 4+$, or $\mathrm{CD} 8+$ cell frequency in peripheral blood, as well as no modification of $\mathrm{CB} 1$ or $\mathrm{CB} 2$ expression on those same cells. Quite interestingly, Centonze et al. (2009) also reported no efficacy of nabiximols on pain or spasticity in their patient cohort. In this regard, Sorosina et al. (2018) in their study performed an analysis of MS patients with spasticity responding to nabiximols, reporting in whole blood upregulation of genes belonging to the ribosome pathway and downregulation of genes related to immune system, cell motility/ migration and nervous system.

The remaining two studies are on the contrary clinical trials aimed at evaluating the effects of cannabinoids on MS symptoms. Neither studies employed pure CBD as test drug, nonetheless they were included in the analysis since both employed preparations containing significant amounts of CBD and reported data on patients' peripheral immune functions. The first one (Killestein et al. 2003) is a crossover study including 16 MS patients (10 with SPMS and 6 with PPMS), receiving the following treatments each for 4 consecutive weeks, separated by 4 -weeks washout: dronabinol, $C$. sativa whole plant standardized extract (containing THC $2.5 \mathrm{mg}$ and 20-30\% CBD), and placebo. All treatments had no effects either on the frequency of circulating $\mathrm{T}$ and $\mathrm{B}$ cells, monocytes and NK cells, or on plasma levels of TNF- $\alpha$, IL-12p40, IL-12p70 and IL-10, or on ex vivo proliferation of T cells. Remarkably, treatment with the $C$. sativa whole plant extract resulted in increased TNF- $\alpha$ production in ex vivo LPS-stimulated whole blood, and 7 MS patients with dronabinol- and/or $C$. sativa whole plant extract-related adverse event scores above median had also an increase in plasma IL-12p40 (Killestein et al. 2003).

The second one (Katona et al. 2005) reports data derived from the Cannabinoids in MS (CAMS) study, a large randomized controlled trial to evaluate the therapeutic efficacy of cannabinoids (Zajicek et al. 2005). In the original study, 630 patients with stable MS with muscle spasticity from 33 UK centres were randomised to receive oral $\Delta 9$-THC, a whole plant extract standardized to $\triangle 9$-THC:CBD 2:1 (0,25:0,125 mg, Cannador), or placebo. Results of the whole study showed evidence of a small treatment effect on muscle spasticity (Zajicek et al. 2005). Katona et al. (2005) report data from 100 of those patients (74 SPMS and 26 PPMS), showing no effect on serum levels of IFN- $\gamma$, IL-10, IL-12 or CRP, or on frequency of circulating IFN- $\gamma$-expressing CD3 $+\mathrm{T}$ cells.

Ex vivo/in vitro studies include a report showing that nabiximols dose-dependently reduces TNF- $\alpha$, IL- 6 and IL10 release in cultured PBMC from both healthy subjects and from MS patients, ether untreated and treated with nabiximols for pain and spasticity (Sorosina et al. 2018), as well as an investigation showing that $\mathrm{CBD}$ in the $\mu \mathrm{M}$ concentration range suppressed proliferation, decreased TNF- $\alpha-$, IFN- $\gamma-$, and IL-17A-expressing CD3+ T cells as well as IL-2- and GM-CSF-expressing CD3+ T cells more effectively in cells from MS patients than from healthy subjects (Zgair et al. 2017). In both studies, CBD alone (Zgair et al. 2017) or together with $\triangle 9$-THC (Sorosina et al. 2018), was active in the $\mu \mathrm{M}$ concentration range.

\section{Discussion}

Several lines of evidence strongly support the general immunomodulatory properties of $\mathrm{CBD}$, which is an established anti-inflammatory agent endowed even with some immunosuppressive properties (reviewed in Nichols and Kaplan (2020) and in Peyravian et al. (2020)). In agreement with such favourable premises, our systematic review retrieved a total of 20 in vivo and ex vivo/in vitro studies of CBD in preclinical models of MS, all in rodents and including several different animal models of EAE, consistently pointing to CBD as effective in reducing the clinical and histological severity of EAE in animals, as well as to inhibit relevant encephalitogenic cellular activities in in vitro models. On the contrary, just a few studies could be identified in the clinical setting, the vast majority of them reporting no effects on immune profiles or functions. Such a major discrepancy between preclinical and clinical studies requires careful consideration, in order to identify likely explanations.

Most of the animal studies were performed in C57BL/6 J mice immunized with $\mathrm{MOG}_{35-55}$, a chronic animal model of MS which resembles primary and secondary progressive MS, and which mostly involves CD8+, CD4+, Th17, and regulatory $\mathrm{T}$ cells, B cells, as well as monocytes and macrophages (Procaccini et al. 2015; Kipp et al. 2017). CBD was however also effective in SJL/J mice immunized with $\mathrm{PLP}_{139-151}$, which better recapitulates relapsing-remitting MS, as well as 


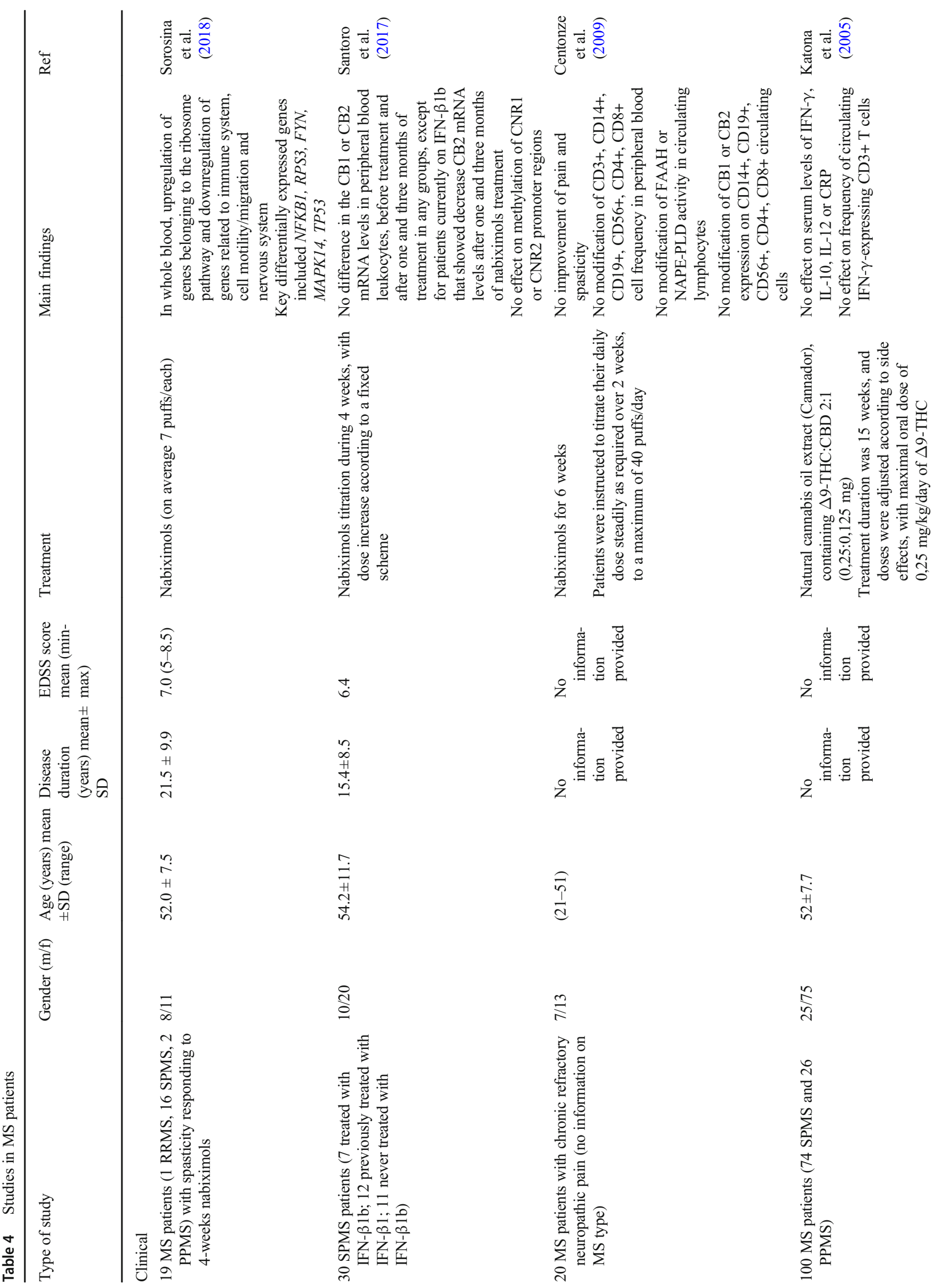




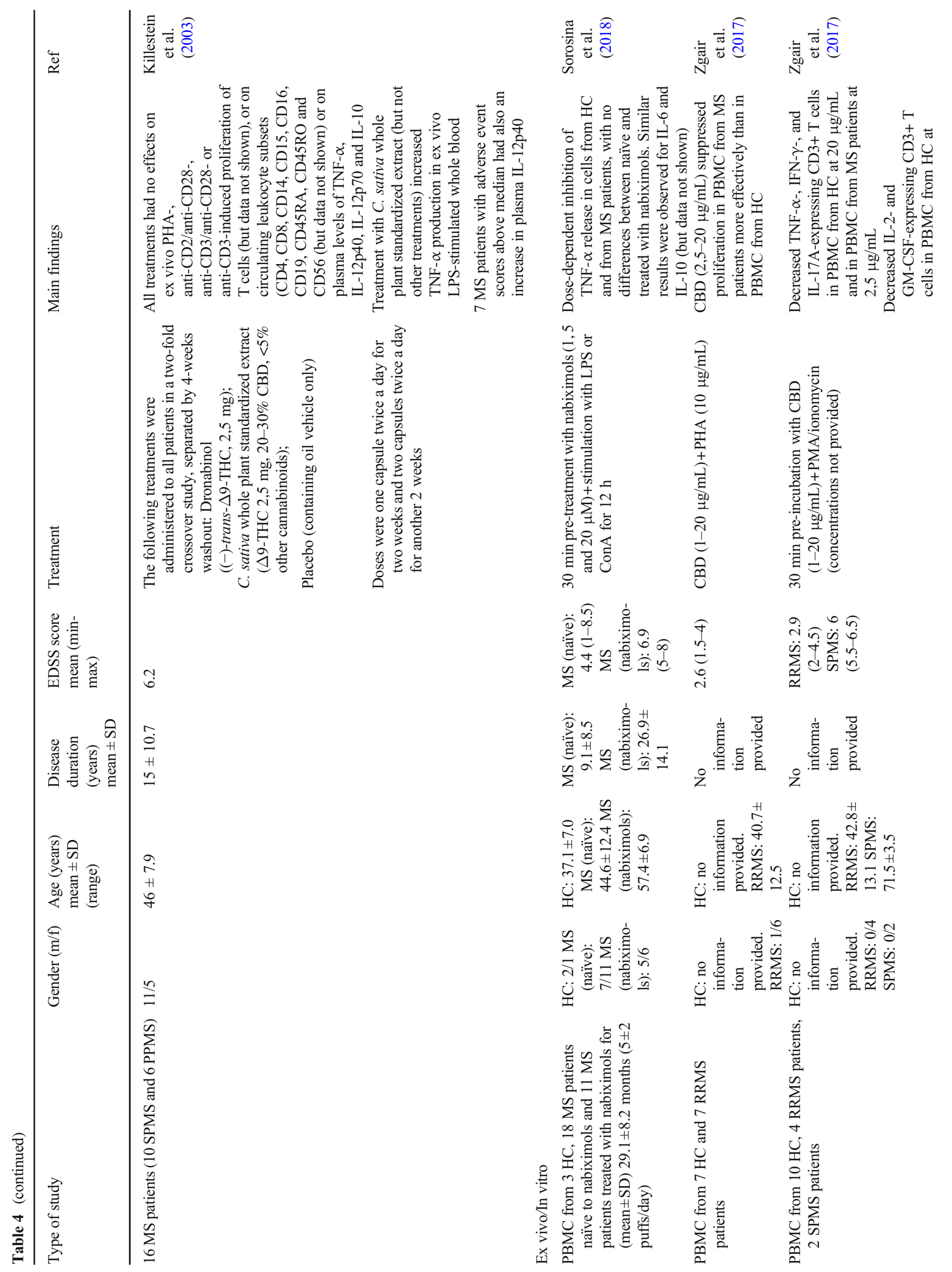




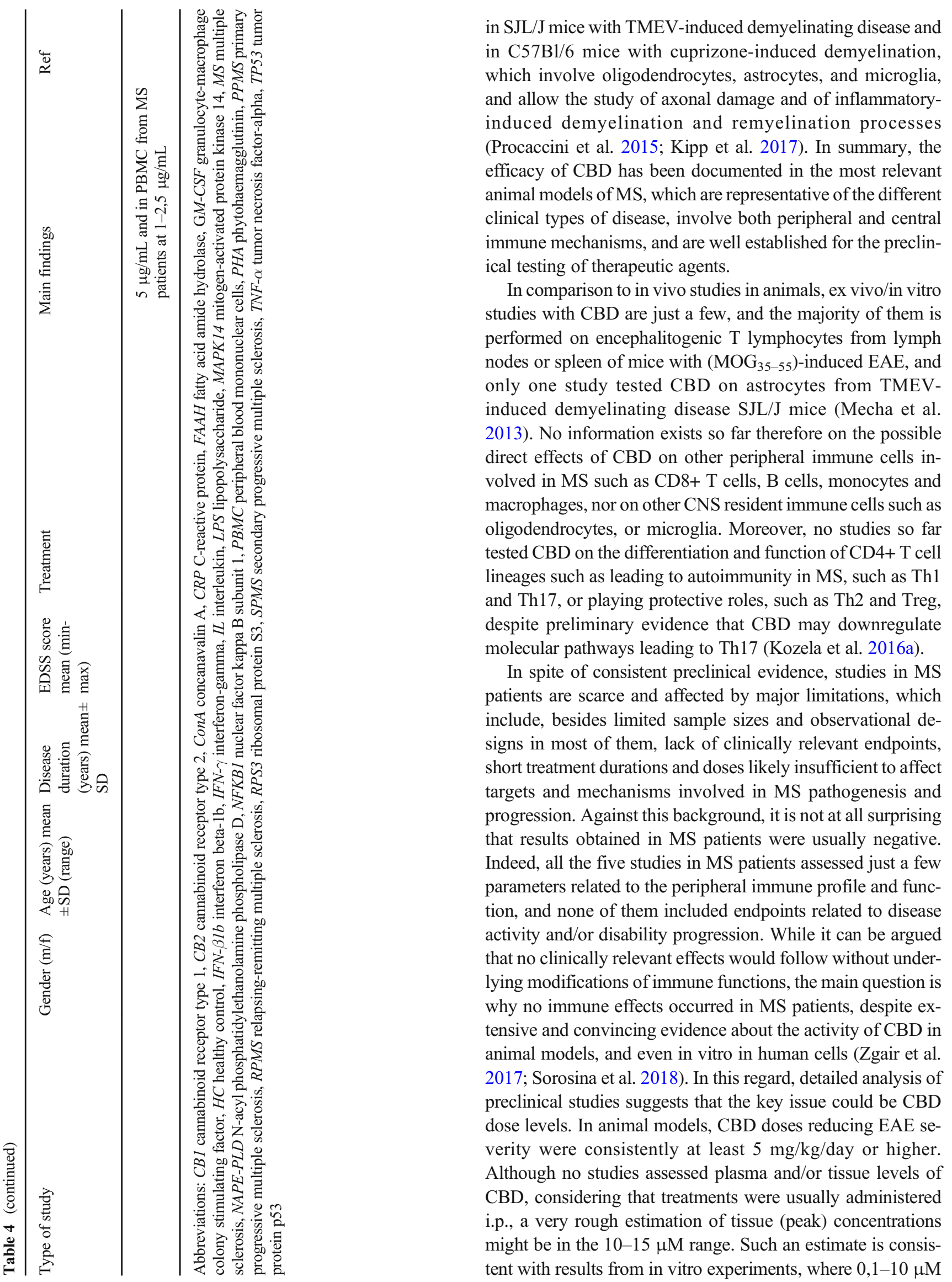


CBD was commonly used. Remarkably, at those concentrations CBD is effective on encephalitogenic cells from rodents (Kozela et al. 2011, 2013, 2015, 2016a; Mecha et al. 2013; González-García et al. 2017; Yang et al. 2019) as well as on T cells from healthy subjects and MS patients (Zgair et al. 2017; Sorosina et al. 2018).

In clinical studies, on the contrary, CBD doses were consistently lower. In studies where nabiximols was used, a maximum of 40 puffs/day was administered by Centonze et al. (2009), while Sorosina et al. (2018) and Santoro et al. (2017) used lower daily doses. Nabiximols contains $2,5 \mathrm{mg}$ of CBD per puff, which makes $100 \mathrm{mg}$ /day (or about $1,4 \mathrm{mg} / \mathrm{kg} /$ day for a $70-\mathrm{kg}$ subject). Katona et al. (2005) administered natural cannabis oil extract with maximal oral dose of $0,25 \mathrm{mg} / \mathrm{kg} / \mathrm{day}$ of $\Delta 9$-THC. The oil extract contains $\Delta 9$ THC:CBD 2:1, thus it is inferred that the maximal oral dose of CBD was $0,125 \mathrm{mg} / \mathrm{kg} / \mathrm{day}$ (or about $8,75 \mathrm{mg} /$ day for a $70-\mathrm{kg}$ subject). Finally, Killestein et al. (2003) used a C. sativa whole plant extract standardized to $\Delta 9$-THC $2,5 \mathrm{mg} / \mathrm{capsule}$, with 20-30\% CBD, and administered two capsules twice a day, which makes a total of $10 \mathrm{mg} /$ day $\triangle 9-\mathrm{THC}$ and a putative $2-3 \mathrm{mg} /$ day CBD. Available pharmacokinetic studies in humans (reviewed by Millar et al. 2018) show that administration of CBD, either by oromucosal spray in 5 to $20 \mathrm{mg}$ doses (but, at least in one study, also up to $60-90 \mathrm{mg}$ ) or by oral capsules containing CBD $10 \mathrm{mg}$, consistently provide peak plasma concentration in the $1-4 \mathrm{ng} / \mathrm{mL}$ range, corresponding to about $0,01 \mu \mathrm{M}$, thus well below theoretical concentrations reached in animal studies as well as, most importantly, well below concentrations which are effective in in vitro models based on either animal or human cells.

On these basis, it is proposed that - for CBD to be effective in humans as an immunomodulatory drug - higher doses should be considered. Indeed, also from a general point of view which doses of CBD are more effective in different disease states remain a matter of debate, nonetheless a recent review investigating what doses have been applied in clinical populations in a variety of medical contexts showed that CBD was well tolerated at oral doses up to $50 \mathrm{mg} / \mathrm{kg} /$ day (Millar et al. 2019), corresponding to a total amount 3,5 g/day for a 70-kg subject. Recently the U.S. FDA and the EMA recently approved CBD (as Epidiolex ${ }^{\circledR}, \mathrm{GW}$ Pharmaceuticals) to treat rare forms of epilepsy in children, with maximum doses of $10 \mathrm{mg} / \mathrm{kg}$ twice a day. Remarkably, a recent study in children and adults with treatment-refractory epilepsy showed that Epidiolex ${ }^{\circledR}$ could be safely increased up to a maximum dosage of $50 \mathrm{mg} / \mathrm{kg} /$ day depending on tolerance and seizure control, with a positive linear correlation between CBD dosage (range from 5 to $50 \mathrm{mg} / \mathrm{kg} /$ day) and level (range from 7.1 to $1200 \mathrm{ng} / \mathrm{mL}$ ) (Szaflarski et al. 2019). The concentration of $1200 \mathrm{ng} / \mathrm{mL}$ corresponds to about $3,8 \mu \mathrm{M}$, thus quite close to the about $8 \mu \mathrm{M}$ CBD which was shown by Zgair et al. (2017) to suppress proliferation and proinflammatory cytokine production in $\mathrm{CD} 3+\mathrm{T}$ cells from MS patients. The study by Szaflarski et al. (2019) should thus be taken as a proof of concept that CBD concentrations, which in vitro exert immunomodulatory effects relevant for MS, can be safely reached in humans provided that appropriate doses are used. Studying the peripheral immune profile and function in people with epilepsy receiving Epidiolex ${ }^{\circledR}$, and in particular in those on high dose regimens, could also provide useful information to properly design clinical studies of CBD as immune modulator in MS patients, in terms of dosing regimens as well as of relevant endpoints to be measured.

CBD has a complex pharmacological profile (Table 1), however the molecular targets acted upon by CBD were examined in just a few studies, and only in in vitro models based on rodent cells. Available results suggest no involvement of either CB1, CB2, 5-HT1A, TRPV1 or PPAR $\gamma$ in CBDdependent reduction of IL-17 secretion from $\mathrm{T}$ cells (Kozela et al. 2013), or of CB1 or CB2 in CBD-induced inhibition of T cell proliferation (Kozela et al. 2011), or of CB1, CB2 or GPR55 in CBD-induced inhibition of $\mathrm{MOG}_{35-55}$ /IL-12-induced IL-6 secretion and increased apoptosis in mouse encephalitogenic spleen cells (González-García et al. 2017). The only positive evidence presently available suggests a role for $\mathrm{A}_{2 \mathrm{~A}}$ receptors in CBD-induced reduction of CCL2 secretion from mouse astrocytes (Mecha et al. 2013). In this regard, it may be of interest that EHP-101, a new chemical entity derived from CBD, acting as dual PPAR $\gamma$ and CB2 agonist as well as activator of the hypoxia inducible factor (HIF) pathway, has been shown to exert anti-inflammatory effects in vitro in murine RAW264.7 and BV2 cell lines and rat primary microglia cells, and to reduce EAE severity in $\mathrm{C} 57 \mathrm{BL} / 6 \mathrm{~J}$ mice with either $\left(\mathrm{MOG}_{35-55}\right)$-induced EAE or with cuprizone-induced demyelination, as well as in the TMEV-IDD SJL/J mouse model (Navarrete et al. 2018, 2020). Taken as a whole, available evidence does not allow any meaningful conclusion about molecular targets involved in the effects of CBD in EAE and possibly in MS, unless that apparently its therapeutic potential cannot be explained just by means of a single target. Meanwhile, evidence about the activity of synthetic derivatives of CBD, such as HU-446 and HU-465 which exert inhibitory effects on encephalitogenic $\mathrm{MOG}_{35-55}$-specific $\mathrm{T}$ cell line from lymph nodes of C57BL/ 6 mice (Kozela et al. 2016b), emphasize the relevance of CBD also as a molecular scaffold to develop novel drugs targeting the immune system.

In summary, available preclinical evidence in rodent models of EAE strongly support CBD as an effective immunomodulating and disease-modifying drug, although its cellular and molecular targets remain largely uninvestigated. In contrast, despite the established use of CBD-containing drugs in MS, evidence in patients is limited and usually negative, possibly due mainly to inadequate therapeutic regimens, in terms of both dose and duration. A 
research agenda aiming at the proper assessment of CBD as an immunomodulating drug for MS should include, first of all, a detailed characterization of the effects of CBD on the key cellular and molecular mechanisms involved in MS pathogenesis and progression, including for example: (i) peripheral activation of pro-inflammatory $\mathrm{T}$ cells resulting from their interaction with antigen-presenting cells, such as macrophages; (ii) migration of activated $\mathrm{T}$ cells through the bloodbrain barrier, mediated by adhesion molecules, proteases and chemokines; (iii) reactivation of $\mathrm{T}$ cells in the CNS through interaction with microglia, with subsequent secretion of proinflammatory cytokines, such as IFN- $\gamma$ or IL-2, leading to activation of macrophages, other $\mathrm{T}$ cells and $\mathrm{B}$ cells; (iv) inflammation-induced damage of oligodendrocytes, resulting in destruction of the myelin sheath by cytotoxic mediators, such as TNF- $\alpha$ and oxidative radicals; (v) differentiation of $\mathrm{B}$ cells into plasma cells, secreting demyelinating antibodies in turn attracting macrophages, and triggering the complement cascade (Yamout and Alroughani 2018; Hemmer et al. 2002). Only fragmentary evidence exists so far, nearly only in $\mathrm{T}$ cells and mostly in rodent models, and much more work is needed, primarily in human cells. The most important and urgent needs regards however the development of well-designed clinical trials, aimed at testing adequate doses of CBD on clinically relevant efficacy endpoints Indeed, based on available pharmacokinetic and therapeutic studies in other disease conditions, and in particular in epilepsy, doses higher than those used so far should be tested to properly assess the immunomodulatory potential of CBD in MS. Future studies should always include careful monitoring of plasma concentration in relation to dosing regimens, to collect key information which will allow to deal with the inherent pharmacokinetic heterogeneity of CBD, which is likely due at least in part to pharmacogenetic factors. Most importantly, such trials should include as primary efficacy endpoints clinically relevant measures of disease activity and/or disability progression, or at least evidence of magnetic resonance imagingassessed disease activity, relapses and progression, neurological rating scales, measures of cognitive impairment, fatigue scales, as assessed by patient and physician, as well as patient reported outcomes (CHMP, 2015). Nevertheless, even based on the limited evidence so far available, CBD appears as a highly promising drug with significant immunomodulating and disease-modifying potential for MS, added benefits residing in its well established safety and tolerability profile.

Supplementary Information The online version contains supplementary material available at https://oi.org/10.1007/s11481-021-09982-7.

Acknowledgements The Authors gratefully acknowledge the support provided by the Italian Foundation for Multiple Sclerosis (FISM, Projects \#2002/R/18 and \#2003/R/67) and by the United States of America National Multiple Sclerosis Society (NMSS, Pilot Projects PP0791 and PP1255), which contributed to the development of some of the ideas and of the experimental research reviewed in the text. Alessia Furgiuele developed a research program on innovative pharmacological approaches to modulate peripheral immunity and their relevance for autoimmune and neurodegenerative disease, as part of her work for the $\mathrm{PhD}$ Course in Clinical and Experimental Medicine and Medical Humanities, University of Insubria (XXXIV Cycle).

Author Contribution MC and FM defined the topic and developed the literature search strategy together with $\mathrm{AF}$. AF performed the literature search screening for relevant titles and abstracts, finally selecting the titles included in the review, which were cross-validated by MC. MC wrote the first draft of the manuscript, with the exception of the paragraph dealing with CBD PGx, which was drafted by MF. AF drafted tables and figures. All authors were involved in critically revising the article for important intellectual content, and all authors approved the final version to be published. All authors agree to be accountable for all aspects of the work in ensuring that questions related to the accuracy or integrity of any part of the work are appropriately investigated and resolved, and declare to have confidence in the integrity of the contributions of their co-authors.

Funding Open Access funding provided by Università degli Studi dell'Insubria.

\section{Compliance with Ethical Standards}

Conflict of Interest The authors declare that they have no conflict of interest.

Open Access This article is licensed under a Creative Commons Attribution 4.0 International License, which permits use, sharing, adaptation, distribution and reproduction in any medium or format, as long as you give appropriate credit to the original author(s) and the source, provide a link to the Creative Commons licence, and indicate if changes were made. The images or other third party material in this article are included in the article's Creative Commons licence, unless indicated otherwise in a credit line to the material. If material is not included in the article's Creative Commons licence and your intended use is not permitted by statutory regulation or exceeds the permitted use, you will need to obtain permission directly from the copyright holder. To view a copy of this licence, visit http://creativecommons.org/licenses/by/4.0/.

\section{References}

Al-Ghezi ZZ, Busbee PB, Alghetaa H, Prakash S, Nagarkatti PS, Nagarkatti M (2019a) Combination of cannabinoids, delta-9tetrahydrocannabinol (THC) and cannabidiol (CBD), mitigates experimental autoimmune encephalomyelitis (EAE) by altering the gut microbiome. Brain Behav Immun 82:25-35

Al-Ghezi ZZ, Miranda K, Nagarkatti M, Nagarkatti PS (2019b) Combination of cannabinoids, delta 9-tetrahydrocannabinol and cannabidiol, ameliorates experimental multiple sclerosis by suppressing neuroinflammation through regulation of miRNAmediated signaling pathways. Front Immunol 10:1921

Andre CM, Hausman J-F, Guerriero G (2016) Cannabis sativa: the plant of the thousand and one molecules. Front Plant Sci 7:19

Atalay S, Jarocka-Karpowicz I, Skrzydlewska E (2019) Antioxidative and anti-inflammatory properties of cannabidiol. Antioxidants (Basel) 9:21

Babalonis S, Haney M, Malcolm RJ, Lofwall MR, Votaw VR, Sparenborg S, Walsh SL (2017) Oral cannabidiol does not produce 
a signal for abuse liability in frequent marijuana smokers. Drug Alcohol Depend 172:9-13

Banwell E, Pavisian B, Lee L, Feinstein A (2016) Attitudes to cannabis and patterns of use among Canadians with multiple sclerosis. Mult Scler Relat Disord 10:123-126

Bergamaschi MM, Queiroz RHC, Zuardi AW, Crippa JAS (2011) Safety and side effects of cannabidiol, a Cannabis sativa constituent. Curr Drug Saf 6:237-249

Brenton JN, Schreiner T, Karoscik K, Richter M, Ferrante S, Waldman A, Banwell B (2018) Attitudes, perceptions, and use of marijuana in youth with multiple sclerosis. J Neurol 265:417-423

Buccellato E, Carretta D, Utana A, Cavina C, Speroni E, Grassi G, Candeletti S, Romualdi P (2011) Acute and chronic cannabinoid extracts administration affects motor function in a CREAE model of multiple sclerosis. J Ethnopharmacol 133:1033-1038

Burstein S (2015) Cannabidiol (CBD) and its analogs: a review of their effects on inflammation. Bioorg Med Chem 23:1377-1385

Cassano T, Villani R, Pace L, Carbone A, Bukke VN, Orkisz S, Avolio C, Serviddio G (2020) From Cannabis sativa to cannabidiol: promising therapeutic candidate for the treatment of neurodegenerative diseases. Front Pharmacol 11:124

Centonze D, Mori F, Koch G, Buttari F, Codecà C, Rossi S, Cencioni MT, Bari M, Fiore S, Bernardi G, Battistini L, Maccarrone M (2009) Lack of effect of cannabis-based treatment on clinical and laboratory measures in multiple sclerosis. Neurol Sci 30:531-534

Chen JW, Borgelt LM, Blackmer AB (2019) Cannabidiol: a new hope for patients with Dravet or Lennox-Gastaut syndromes. Ann Pharmacother 53:603-611

CHMP - Committee for Medicinal Products for Human Use (2015) Guideline on clinical investigation of medicinal products for the treatment of multiple sclerosis. EMA/CHMP/771815/2011, Rev. 2

Costiniuk CT, Jenabian MA (2020) Acute inflammation and pathogenesis of SARS-CoV-2 infection: cannabidiol as a potential antiinflammatory treatment? Cytokine Growth Factor Rev 53:63-65

Dobson R, Giovannoni G (2019) Multiple sclerosis - a review. Eur J Neurol 26:27-40

Duchi S, Ovadia H, Touitou E (2013) Nasal administration of drugs as a new non-invasive strategy for efficient treatment of multiple sclerosis. J Neuroimmunol 258:32-40

Elliott DM, Singh N, Nagarkatti M, Nagarkatti PS (2018) Cannabidiol attenuates experimental autoimmune encephalomyelitis model of multiple sclerosis through induction of myeloid-derived suppressor cells. Front Immunol 9:1782

Esposito G, Filippis DD, Cirillo C, Iuvone T, Capoccia E, Scuderi C, Steardo A, Cuomo R, Steardo L (2013) Cannabidiol in inflammatory bowel diseases: a brief overview. Phytother Res 27:633-636

Gallily R, Yekhtin Z (2019) Avidekel Cannabis extracts and cannabidiol are as efficient as Copaxone in suppressing EAE in SJL/J mice. Inflammopharmacology 27:167-173

Gholamzad M, Ebtekar M, Ardestani MS, Azimi M, Mahmodi Z, Mousavi MJ, Aslani S (2019) A comprehensive review on the treatment approaches of multiple sclerosis: currently and in the future. Inflamm Res 68:25-38

Giacoppo S, Galuppo M, Pollastro F, Grassi G, Bramanti P, Mazzon E (2015) A new formulation of cannabidiol in cream shows therapeutic effects in a mouse model of experimental autoimmune encephalomyelitis. Daru 23:48

Giacoppo S, Pollastro F, Grassi G, Bramanti P, Mazzon E (2017) Target regulation of $\mathrm{PI} 3 \mathrm{~K} / \mathrm{Akt} / \mathrm{mTOR}$ pathway by cannabidiol in treatment of experimental multiple sclerosis. Fitoterapia 116:77-84

Gonçalves ED, Dutra RC (2019) Cannabinoid receptors as therapeutic targets for autoimmune diseases: where do we stand? Drug Discov Today 24:1845-1853

González-García C, Torres IM, García-Hernández R, Campos-Ruíz L, Esparragoza LR, Coronado MJ, García Grande A, García-Merino A, Sánchez López AJ (2017) Mechanisms of action of cannabidiol in adoptively transferred experimental autoimmune encephalomyelitis. Exp Neurol 298(Pt A):57-67

Hemmer B, Archelos JJ, Hartung HP (2002) New concepts in the immunopathogenesis of multiple sclerosis. Nat Rev Neurosci 3: 291-301

Hoffmeyer S, Burk O, von Richter O, Arnold HP, Brockmoller J, Johne A, Cascorbi I, Gerloff T, Roots I, Eichelbaum M, Brinkmann U (2000) Functional polymorphisms of the human multidrugresistance gene: multiple sequence variations and correlation of one allele with P-glycoprotein expression and activity in vivo. Proc Natl Acad Sci U S A 97:3473-3478

Hryhorowicz S, Walczak M, Zakerska-Banaszak O, Słomski R, Skrzypczak-Zielińska M (2018) Pharmacogenetics of cannabinoids. Eur J Drug Metab Pharmacokinet 43:1-12

Iannotti FA, Hill CL, Leo A, Alhusaini A, Soubrane C, Mazzarella E, Russo E, Whalley BJ, Di Marzo V, Stephens GJ (2014) Nonpsychotropic plant cannabinoids, cannabidivarin (CBDV) and cannabidiol (CBD), activate and desensitize transient receptor potential vanilloid 1 (TRPV1) channels in vitro: potential for the treatment of neuronal hyperexcitability. ACS Chem Neurosci 5:11311141

Iffland K, Grotenhermen F (2017) An update on safety and side effects of cannabidiol: a review of clinical data and relevant animal studies. Cannabis Cannabinoid Res 2:139-154

Jarrar YB, Lee SJ (2014) Molecular functionality of CYP2C9 polymorphisms and their influence on drug therapy. Drug Metabol Drug Interact 29:211-220

Kathmann M, Flau K, Redmer A, Tränkle C, Schlicker E (2006) Cannabidiol is an allosteric modulator at mu- and delta-opioid receptors. Naunyn Schmied Arch Pharmacol 372:354-361

Katona S, Kaminski E, Sanders H, Zajicek J (2005) Cannabinoid influence on cytokine profile in multiple sclerosis. Clin Exp Immunol 140:580-585

Khatami F, Mohajeri-Tehrani MR, Tavangar SM (2019) The importance of precision medicine in type 2 diabetes mellitus (T2DM): from pharmacogenetic and pharmacoepigenetic aspects. Endocr Metab Immune Disord Drug Targets 19:719-731

Killestein J, Hoogervorst ELJ, Reif M, Blauw B, Smits M, Uitdehaag BMJ, Nagelkerken L, Polman CH (2003) Immunomodulatory effects of orally administered cannabinoids in multiple sclerosis. J Neuroimmunol 137:140-143

Kipp M, Nyamoya S, Hochstrasser T, Amor S (2017) Multiple sclerosis animal models: a clinical and histopathological perspective. Brain Pathol 27:123-137

Klein TW (2005) Cannabinoid-based drugs as anti-inflammatory therapeutics. Nat Rev Immunol 5:400-411

Kozela E, Lev N, Kaushansky N, Eilam R, Rimmerman N, Levy R, BenNun A, Juknat A, Vogel Z (2011) Cannabidiol inhibits pathogenic T cells, decreases spinal microglial activation and ameliorates multiple sclerosis-like disease in C57BL/6 mice. Br J Pharmacol 163:15071519

Kozela E, Juknat A, Kaushansky N, Rimmerman N, Ben-Nun A, Vogel Z (2013) Cannabinoids decrease the Th17 inflammatory autoimmune phenotype. J Neuroimm Pharmacol 8:1265-1276

Kozela E, Juknat A, Kaushansky N, Ben-Nun A, Coppola G, Vogel Z (2015) Cannabidiol, a non-psychoactive cannabinoid, leads to EGR2-dependent anergy in activated encephalitogenic T cells. J Neuroinflammation 12:1

Kozela E, Ana Juknat A, Gao F, Kaushansky N, Coppola G, Voge Z (2016a) Pathways and gene networks mediating the regulatory effects of cannabidiol, a nonpsychoactive cannabinoid, in autoimmune T cells. J Neuroinflammation 13:136

Kozela E, Haj C, Hanuš L, Chourasia M, Shurki A, Juknat A, Kaushansky N, Mechoulam R, Vogel Z (2016b) HU-446 and HU465 , derivatives of the non-psychoactive cannabinoid cannabidiol, 
decrease the activation of encephalitogenic T cells. Chem Biol Drug Des 87:143-153

Lim K, See YM, Lee J (2017) A systematic review of the effectiveness of medical Cannabis for psychiatric, movement and neurodegenerative disorders. Clin Psychopharmacol Neurosci 15:301-312

Loraschi A, Bellantonio P, Bortolon F, Capra R, Cavalla P, Costantino G, Lugaresi A, Martinelli V, Marrosu MG, Patti F, Rottoli M, Salvetti M, Sola P, Solaro C, Klersy C, Marino F, Zaffaroni M, Cosentino M (2016) Use of herbal remedies by multiple sclerosis patients: a nation-wide survey in Italy. Neurol Sci 37:613-622

Lötsch J, Geisslinger G (2011) Pharmacogenetics of new analgesics. Br J Pharmacol 163:447-460

Lowin T, Schneider M, Pongratz G (2019) Joints for joints: cannabinoids in the treatment of rheumatoid arthritis. Curr Opin Rheumatol 31: 271-278

Mazur A, Lichti CF, Prather PL, Zielinska AK, Bratton SM, GallusZawada A, Finel M, Miller GP, Radomin'ska-Pandya A, Moran JH (2009) Characterization of human hepatic and extrahepatic UDP-glucuronosyltransferase enzymes involved in the metabolism of classic cannabinoids. Drug Metab Dispos 37:1496-1504

Mecha M, Feliú A, Iñigo PM, Mestre L, Carrillo-Salinas FJ, Guaza C (2013) Cannabidiol provides long-lasting protection against the deleterious effects of inflammation in a viral model of multiple sclerosis: a role for A2A receptors. Neurobiol Dis 59:141-150

Mechoulam R, Shani A, Edery H, Grunfeld Y (1970) Chemical basis of hashish activity. Science 169:611-612

Millar SA, Stone NL, Yates AS, O'Sullivan SE (2018) A systematic review on the pharmacokinetics of cannabidiol in humans. Front Pharmacol 9:1365

Millar SA, Stone NL, Bellman ZD, Yates AS, England TJ, O'Sullivan SE (2019) A systematic review of cannabidiol dosing in clinical populations. Br J Clin Pharmacol 85:1888-1900

Moher D, Liberati A, Tetzlaff J, Altman DG, PRISMA Group (2009) Preferred reporting items for systematic reviews and meta-analyses: the PRISMA statement. PLoS Med 6:e1000097

Moreno-Martet M, Feliú A, Espejo-Porras F, Mecha M, Carrillo-Salinas FJ, Fernández-Ruiz J, Guaza C, de Lago E (2015) The diseasemodifying effects of a Sativex-like combination of phytocannabinoids in mice with experimental autoimmune encephalomyelitis are preferentially due to $\Delta$ 9-tetrahydrocannabinol acting through CB1 receptors. Mult Scler Rel Dis 4:505-511

Muller C, Morales P, Reggio PH (2019) Cannabinoid ligands targeting TRP channels. Front Mol Neurosci 11:487

Navarrete C, Carrillo-Salinas F, Palomares B, Mecha M, JiménezJiménez C, Mestre L, Feliú A, Bellido ML, Fiebich BL, Appendino G, Calzado MA, Guaza C, Muñoz E (2018) Hypoxia mimetic activity of VCE-004.8, a cannabidiol quinone derivative: implications for multiple sclerosis therapy. J Neuroinflammation 15: 64

Navarrete C, García-Martin A, Garrido-Rodríguez M, Mestre L, Feliú A, Guaza C, Calzado MA, Muñoz E (2020) Effects of EHP-101 on inflammation and remyelination in murine models of multiple sclerosis. Neurobiol Dis 143:104994

NCT02116010. ClinicalTrials.gov (n.d.) Pharmacogenetics of cannabinoid response. Accessed December 15, 2020. https://clinicaltrials. gov/ct $2 /$ show $/$ NCT00678730?term $=$ NCT00678730\&draw $=$ $2 \&$ rank $=1$

NCT02492074. ClinicalTrials.gov (n.d.) Gene-environment-interaction: influence of the COMT genotype on the effects of different cannabinoids - a PET study. Accessed December 15, 2020. https:// clinicaltrials.gov/ct $2 / \mathrm{show} / \mathrm{NCT} 02492074$ ?term= NCT02492074\&draw $=2 \&$ rank $=1$

Nichols JM, Kaplan BLF (2020) Immune responses regulated by cannabidiol. Cannabis Cannabinoid Res 5:12-31

Nichols JM, Kummari E, Sherman J, Yang E-J, Dhital S, Gilfeather C, Yray G, Morgan T, Kaplan BLF (2020) CBD suppression of EAE is correlated with early inhibition of splenic IFN $-\gamma+\mathrm{CD} 8+\mathrm{T}$ cells and modest inhibition of neuroinflammation. J Neuroimm Pharmacol. https://doi.org/10.1007/s11481-020-09917-8(online-ahead-of-print)

O’Sullivan SE, Sun Y, Bennett AJ, Randall MD, Kendall DA (2009) Time-dependent vascular actions of cannabidiol in the rat aorta. Eur J Pharmacol 612:61-68

Oh J, Vidal-Jordana A, Montalban X (2018) Multiple sclerosis: clinical aspects. Curr Opin Neurol 31:752-759

Olson KC, Dellinger RW, Zhong Q, Sun D, Amin S, Spratt TE, Lazarus P (2009) Functional characterization of low-prevalence missense polymorphisms in the UDP-glucuronosyltransferase 1A9 gene. Drug Metab Dispos 37:1999-2007

Pertwee RG (2008) The diverse CB 1 and CB 2 receptor pharmacology of three plant cannabinoids: $\Delta$ 9-tetrahydrocannabinol, cannabidiol and $\Delta 9$-tetrahydrocannabivarin. Br J Pharmacol 153:199-215

Peyravian N, Deo S, Daunert S, Jimenez JJ (2020) Cannabidiol as a novel therapeutic for immune modulation. Immunotargets Ther 9:131140

Procaccini C, De Rosa V, Pucino V, Formisano L, Matarese G (2015) Animal models of multiple sclerosis. Eur J Pharmacol 759:182-191

Rahimi A, Faizi M, Talebi F, Noorbakhsh F, Kahrizi F, Naderi N (2015) Interaction between the protective effects of cannabidiol and palmitoylethanolamide in experimental model of multiple sclerosis in C57BL/6 mice. Neuroscience 290:279-287

Reich DS, Lucchinetti CF, Calabresi PA (2018) Multiple Sclerosis. N Engl J Med 378:169-180

Ribeiro A, Ferraz-de-Paula V, Pinheiro ML, Vitoretti LB, Mariano-Souza DP, Quinteiro-Filho WM, Akamine AT, Almeida VI, Quevedo J, Dal-Pizzol F, Hallak JE, Zuardi AW, Crippa JA, Palermo-Neto J (2012) Cannabidiol, a non-psychotropic plant-derived cannabinoid, decreases inflammation in a murine model of acute lung injury: role for the adenosine $\mathrm{A}(2 \mathrm{~A})$ receptor. Eur J Pharmacol 678:78-85

Rui-Jian Y, Ting-Ting L, Yi-Fang W, Wei-Shan C (2017) Single nucleotide polymorphisms of ABCB1 gene and response to etanercept treatment in patients with ankylosing spondylitis in a Chinese Han population. Med (Baltimore) 96:e5929

Russo EB, Burnett A, Hall B, Parker KK (2005) Agonistic properties of cannabidiol at 5-HT1a receptors. Neurochem Res 30:1037-1043

Sajjadian M, Ragerdi Kashani I, Pasbakhsh P, Hassani M, Ameneh Omidi A, Takzare N, Clarner T, Beyer C, Zendedel A (2017) Protective effects of cannabidiol on cuprizone-induced demyelination in C57BL/6 mice. J Contemp Med Sci 3:278-283

Santoro M, Mirabella M, De Fino C, Bianco A, Lucchini M, Losavio F, Sabino A, Nociti V (2017) Sativex® effects on promoter methylation and on CNR1/CNR2 expression in peripheral blood mononuclear cells of progressive multiple sclerosis patients. J Neurol Sci 379:298-303

Schabas AJ, Vukojevic V, Taylor C, Thu Z, Badyal A, Chan JK, Devonshire V, Traboulsee A, Sayao AL, Carruthers R (2019) Cannabis-based product use in a multiple sclerosis cohort. Mult Scler J Exp Transl Clin 5:2055217319869360

Sorosina M, Clarellia F, Ferrè L, Osiceanu AM, Unal NT, Mascia E, Martinelli V, Comi G, Benigni F, Esposito F, Martinelli Boneschi F (2018) Clinical response to nabiximols correlates with the downregulation of immune pathways in multiple sclerosis. Eur J Neurol 25:e934-e970

Stout SM, Cimino NM (2014) Exogenous cannabinoids as substrates, inhibitors, and inducers of human drug metabolizing enzymes: a systematic review. Drug Metab Rev 46:86-95

Szaflarski JP, Hernando K, Bebin EM, Gaston TE, Grayson LE, Ampah SB, Moreadith R (2019) Higher cannabidiol plasma levels are associated with better seizure response following treatment with a pharmaceutical grade cannabidiol. Epilepsy Behav 95:131-136

Taylor L, Gidal B, Blakey G, Tayo B, Morrison GA (2018) Phase, I, randomized, double-blind, placebo-controlled, single ascending dose, multiple dose, and food effect trial of the safety, tolerability 
and pharmacokinetics of highly purified cannabidiol in healthy subjects. CNS Drugs 32:1053-1067

Thompson AJ, Baranzini SE, Geurts J, Hemmer B, Ciccarelli O (2018) Multiple sclerosis. Lancet 391:1622-1636

Werk AN, Cascorbi I (2014) Functional gene variants of CYP3A4. Clin Pharmacol Ther 96:340-348

Yadav V, Bever C Jr, Bowen J, Bowling A, Weinstock-Guttman B, Cameron M, Bourdette D, Gronseth GS, Narayanaswami P (2014) Summary of evidence-based guideline: complementary and alternative medicine in multiple sclerosis: report of the guideline development subcommittee of the American Academy of Neurology. Neurology 82:1083-1092

Yamout BI, Alroughani R (2018) Multiple Sclerosis. Semin Neurol 38: 212-225

Yang X, Bam M, Nagarkatti PS, Nagarkatti M (2019) Cannabidiol regulates gene expression in encephalitogenic T cells using histone methylation and noncoding RNA during experimental autoimmune encephalomyelitis. Sci Rep 9:1-10

Zajicek JP, Sanders HP, Wright DE, Vickery PJ, Ingram WM, Reilly SM, Nunn AJ, Teare LJ, Fox PJ, Thompson AJ (2005) Cannabinoids in multiple sclerosis (CAMS) study: safety and efficacy data for 12 months follow up. J Neurol Neurosurg Psychiatry 76:1664-1669

Zgair A, Lee JB, Wong JCM, Taha DA, Aram J, Di Virgilio D, McArthur JW, Cheng Y-K, Hennig IM, Barrett DA, Fischer PM, Constantinescu CS, Gershkovich P (2017) Oral administration of cannabis with lipids leads to high levels of cannabinoids in the intestinal lymphatic system and prominent immunomodulation. Sci Rep 7:14542

Zhou T, Ahmad TK, Alrushaid S, Pozdirca M, Ethans K, Intrater H, Le T, Burczynski F, Kong J, Namaka M (2019) Therapeutic impact of orally administered cannabinoid oil extracts in an experimental autoimmune encephalomyelitis animal model of multiple sclerosis. Biochemì and Biophys Res Commun 516:373-380

Zurier RB, Burstein SH (2016) Cannabinoids, inflammation, and fibrosis. FASEB J 30:3682-3689

Publisher's Note Springer Nature remains neutral with regard to jurisdictional claims in published maps and institutional affiliations. 